\title{
External Dynamics Influencing Tattooing Among College Students: A Qualitative Analysis
}

Michael W. Firmin

Cedarville University, firmin@cedarville.edu

Luke M. Tse

CedarvilleUniversity, tsel@cedarville.edu

Janna B. Foster

Florida Institue of Technology

Tammy L. Angelini

Eastern University

Follow this and additional works at: http://digitalcommons.cedarville.edu/ psychology_publications

Part of the Personality and Social Contexts Commons, and the Social Psychology and Interaction Commons

\section{Recommended Citation}

Firmin, M., Tse, L., Foster, J., \& Angelini, T. (2012). External dynamics influencing tattooing among college students: A qualitative analysis. Journal of College Student Development, 53, 76-90.

This Article is brought to you for free and open access by DigitalCommons@Cedarville, a service of the Centennial Library. It has been accepted for inclusion in Psychology Faculty Publications by an authorized administrator of DigitalCommons@Cedarville. For more information, please contact digitalcommons@cedarville.edu. 


\title{
External Dynamics Influencing Tattooing Among College Students: A Qualitative Analysis
}

\author{
Michael Firmin Luke Tse Janna Foster Tammy Angelini
}

The study utilized qualitative research methodology to assess external dynamics and their influences on tattooing practices among college students. Twenty-four undergraduates supplied in-depth interviews regarding the external variables related to college students' decisions to tattoo. The present research follows (Tse, Firmin, Angelini, \& Foster, 2006), which reported findings regarding college students' internal dynamics for tattoo choices. Present findings suggest that health concerns, parental and peer influences, and social stigmas are particularly cogent external influencers in college students' decisions to tattoo.

Ancient tattooing practices have been prevalent in nearly every culture at some point in the past few thousand years (Koch, Roberts, \& Cannon, 2005). In the Western world, tattoos most often have been associated with criminals, gangs, or the military. These prevalent social stigmas, along with others associated with gender and race, continue to pose a concern for those who seek to tattoo. More recently, tattoos sometimes indicate risk-taking behaviors, including violence, drugs and alcohol, suicide, criminal behavior, and unprotected sexual activity, especially among adolescents (Roberti, Storch, \& Bravata, 2004). Men with tattoos often receive negative feedback, but generally they have received a higher level of acceptance than have tattooed women (Hawkes, Senn, \& Thorn, 2004). Available data suggests, in sum, that tattooing carries some tendencies toward negative stereotyping.
For generations, another major concern among those who tattoo has been health issues. Despite growing technology and regulations for obtaining a state license to tattoo, numerous risks exist, including infections, allergic reactions, and disease (Armstrong, Owen, Roberts, \& Koch, 2002a). Tattooing has the potential of leading to serious blood-borne diseases, such as HIV, syphilis, or hepatitis $\mathrm{B} / \mathrm{C} / \mathrm{D}$ viruses (Millner $\&$ Eichold, 2001). Serosanguinous fluids are released during each tattooing procedure; this can lead to the transmission of hepatitis B and $\mathrm{C}$ between the client and artist (Armstrong et al., 2002a). Most often these risks occur only due to the use of nonsterile tools by amateur artists. Particular precautions may help avoid common risks; using state-licensed facilities helps to reduce the known physical risks involved with tattooing. Additionally, the U.S. Food and Drug Administration identified particular pigments that are less likely than others to cause allergic reactions (Millner $\&$ Eichold, 2001).

Despite the health risks and the prevalent stigmas attached with tattooing, tattoos recently have become more popular in American culture than they have been during past decades (Sanders, 1988). Although the phenomenon is not new for college students, celebrities sometimes flaunt their tattoos to attract attention, weakening the historical negative stigma against tattooing practices (Frederick $\&$ Bradley, 2000). Consequently, tattooing is

Michael W. Firmin is Professor of Psychology at Cedarville University. Luke M. Tse is Associate Professor of Psychology at Cedarville University. Janna Foster is a graduate student at the Florida Institute of Technology. Tammy Angelini is a graduate student at Eastern University. 
more popular among college students, although some college students likely have engaged in the practice for generations. Because celebrities have flaunted their tattoos and the media have given prominent attention to them at times for their actions, to some degree tattooing practices have become more mainstream than they were in previous generations.

Among the general population, tattooing practices range from simple to extreme. Also, some individuals choose to cover their tattoos with clothing. Prices for tattoos vary also-particularly depending on the size of the object(s). Currently, the research literature does not indicate the potential impact that demographics have on tattooing practices (e.g., gender, ethnicity, or socioeconomic factors). Also unknown are factors that load into students' decisions to etch particular types of tattoos. Naturally, these information gaps provide salient needs for future research in order to better provide an overall understanding of tattooing practices and points to a significant need in the research literature.

Increasingly, individuals from a cross-section of socioeconomic backgrounds have been documented as wearing tattoos (Armstrong et al., 2002a). Schildkrout (2004) noted,

In the past three decades, Western body art has not only become a practice, and in some quarters a fashion, that has crossed social boundaries of class and gender, 'high' culture and 'low,' but also it has been greatly influenced by 'tribal' practices, past and present.” (p. 322)

The latest acceptance of tattooing practices has been favorably referred to as the "tattoo renaissance." Frederick and Bradley (2000) reported that in 1972 , only an estimated $0.1 \%$ of the U.S. population was tattooed, whereas in 1995 these numbers increased to over $5 \%$ of the population (note, however, that estimates range from 12 to 20 million Americans).
Coe, Harmon, Verner, and Tonn (1993) conducted research relating to the acceptance of tattoos, specifically on male bodies. The participants of this study described themselves as uninfluenced by external factors with regard to tattoos. However, the majority obtained tattoos following or concurrent with their close peers receiving a tattoo. Although most of the men did not have tattoos that were readily visible, many acknowledged that they often would receive admiration from women following tattoo disclosures. Most of the participants in the study mentioned that their immediate family members either did not accept their tattoo or they were ignorant of it. Overall, Coe, et al. concluded that tattooing is a highly social process and frequently it is a popular topic of conversation among tattooed individuals.

Armstrong et al. (2002a) were the first published researchers to explicitly focus on student tattooing practices. Armstrong, Owen, Roberts, and Koch (2002b) analyzed the influence of image, identity, family, and friends related to tattooing. Both tattooed and nontattooed participants exhibited a positive, supportive view of tattooed people, with a lack of stereotypical, negative stereotypes. College students in Armstrong et al.'s (2002b) sample related a general support for persons choosing to tattoo. Comparatively, there was little influence and support shown by family members in that sample.

In a subsequent project, Armstrong, Roberts, Owen, and Koch (2004) further studied the social influences related to college student tattooing. They concluded that, unlike family members, friends tend to be a major support source for college students, both during and the after the tattooing process. Most of the participants denied that their decision to tattoo was influenced by friends, family, or popular figures. However, there was a distinct affiliation or connection among the tattooed 
individuals that they did not experience with nontattooed individuals. Because Armstrong et al. (2004) did not conduct longitudinal research, appraising groups of students over time, it is unknown whether college students ascribe their tattoo meanings as durable. It also is unknown whether or not they later regret the decisions made during their college years.

Frederick and Bradley (2006) reported findings from a group of nonclinical participants whom they assessed regarding motivations for tattooing practices. The sample included a group of 53 college students who were administered a survey regarding their motivations to obtain body tattoos. Participants also completed the Existential Anxiety Scale, the Vitality Scale, the Psychopathy Scale, and Global Self-Esteem Scale. We interpreted the findings of the study through Ryan and Deci's (2000) self-determination theory of motivation. Findings showed that $76 \%$ of the individuals in their sample indicated having obtained tattooed for extrinsically, rather than intrinsically, motivated reasons. Further, 91\% of the individuals indicated their experiences reflected autonomous and positive behaviors. This finding was supported by the fact that their depression scores were significantly lower than a control group of nontattooed individuals. There were no additional differences between the groups on the scales used in Frederick and Bradley's sample.

We believe that the work of Frederick and Bradley (2006) warrants follow up at this time. Using survey and personality testing methodology, they provided some broad treatment regarding this important subject of tattooing decisions among college students. Taking this research to the next level seemingly would involve applying qualitative methods (Flick, 2002). As Johnson and Christensen (2004) noted, quantitative and qualitative research studies should work in synchrony with each other-rather than being viewed as competitively or exclusionary. Particular to the present study, we sought to assess Frederick and Bradley's topic at a research level where more in-depth descriptions and explanations could be assessed from student participants. Also, "giving voice" (Ten Have, 2004) to the students' decision choices allows the reader and scholar to heuristically build future research studies in ways that will enhance potential hypotheses to be tested by the quantitative researchers in this domain (Mason, 2002).

\section{METHOD \\ Participants}

Our sample comprised 24 tattooed participants from a comprehensive, Midwest university. We selected the sample from a group of 64 students at the university who replied to a campus-wide e-mail requesting self-disclosure as having been tattooed. All of the students were Caucasian, ranging in age from 18 to 32 years. Minorities were not denied the invitation for voluntary participation. Rather, because only $6 \%$ of the overall student body at this particular university were minority students, we decidedly focused on Caucasians as the target population in this particular study. A homogeneous sample generally is preferable in qualitative research studies, because themes are more likely to be clearly derived from the data (Creswell, 2007). Moreover, we intended to potentially target a future study that would focuses specifically on various American minority college students (e.g., Blacks, Hispanics, Asians, Native Americans, etc.) and their tattoo practices and perceptions.

Fifteen of the participants in our sample were female and nine were male. Their academic class ranged from freshmen to seniors. We asked individuals who responded to the e-mail to complete an initial questionnaire, detailing the story of their tattoo experience. We selected the final participants for the present study 
based on the criteria of having one or more tattoos that were not solely symbols of any form of religious affiliation. Again, in an effort toward maintaining homogeneity of sample, we later conducted a specifically focused study of religiously related tattoos (Firmin, Tse, Foster, $\&$ Angelini, 2008). Consequently, we excluded that particular variable from the present study, using criterion sampling in the traditional qualitative protocol (Bogdan \& Biklen, 2007). Obviously, the names used in the present article for reading clarity are pseudonyms.

\section{Procedure}

We conducted two interview waves following Firmin's (2006) research protocol for qualitative interviewing. The first wave began with an initial pre-interview questionnaire. The questions posed, included: Where did you get your tattoo done? How much did it cost? How many family members had tattoos before you got your first tattoo [Name $\&$ relation]? How many friends do you know that had tattoos before you got your first tattoo? Additionally, we engaged participants in a semistructured, in-depth interview (Seidman, 2006), which was completed by each of the study's 24 participants. We recorded and transcribed data from the first wave of interviews. Following analysis of the data from the first wave, we chose participants for the second wave based on initial potential themes that emerged inductively from the transcripts. In accordance with our longterm approach to qualitative methodology, axial coding (using deductive methods) were not employed - rather, we relied on inductive or open-coding protocol. We garnered second wave interviews based on particular participants' responses, needs for clarification at points, more thick descriptions from initial accounts, and elaborations where information initially seemed inconsistent at points (Silverman \& Marvasti, 2008). We asked individuals to supply either photos or drawings of their tattoo(es). We did not ask participants to reveal their actual tattoo(s) due to the personal nature and location of some designs.

We coded data from the two interviews following Maxwell's (2005) open structure. As such, we analyzed the data inductively, bracketing our own preconceptions (Raffanti, 2006), and did not impose any predetermined categories onto the data set. We used constant comparison among the data in order to generate potential constructs for analysis. This included asking key questions and conducting organizational review and concept mapping (Gay, Mills, \& Airasian, 2008). We assessed codes partially by assessing frequency of words, phrases, and general constructs (Bereska, 2003; Marshall, 2002). Regular meetings among the researchers provided checks of internal validity (Daytner, 2006) as the research process unfolded and while we re-read the transcripts and interviewed participants. The findings reported in the present article reflect the plenary agreement among the study's authors and consensus of perspectives vis-à-vis the participants. When collecting data, we achieved saturation (Guest, Bunce, \& Johnson, 2006), as adding additional participants to the sample were not adding substantial amounts of new potential findings. Consequently, we believe the present sample size was adequate for the intended objective of the present study. Particularly, we stopped interviewing at 24 students because as saturation had occurred, additional students were no longer needed. We eventually discarded some potential themes due to lack of support or because they were not representative of most participants (Fereday \& Muir-Cochrane, 2006). The final four themes were established, following the analysis of the second wave of interviews. Member checks (Merriam, 2002) by key informants in the sample helped support the study's overall conclusions given that the participants were in general agreement with the themes reported in the present article. 
Internal validity for the study was enhanced also through the establishment of data trails (Arminio \& Hultgren, 2002). This involved grounding each of the findings presented in this article to particular data in the participants' transcripts. This protocol has the benefits of ensuring that sufficient data support our conclusions and also assisting potential future researchers who wish later to build on our present research study. Support for generating this audit trail was augmented through use of qualitative research software, NVIVO-8 (Lewins \& Silver, 2007). In sum, our intent was to design a study that would meet the rigor required by apt qualitative research standards (De Wet \& Erasmus, 2005) and thoroughness in executing excellence in methodology (Cope, 2004; Morse, Barrett, Mayan, Olson, \& Spiers, 2002).

We fully recognize the ongoing debate among qualitative research experts regarding the role of theory when interpreting both phenomenological and grounded theory qualitative findings (Raffanti, 2006). Some purport that theory is a legitimate and useful means for interpreting findings from qualitative research (Strauss \& Corbin, 1994), whereas the more traditional model advocates restrained discipline in this regard (Glaser, 1992). In the qualitative tradition, Strauss and Glaser (1967) have undergone a rift from their original publication regarding the role of theory in qualitative methodology. By training and through previous research publication, we are philosophically committed to the latter approach. That is, we believe qualitative findings best are presented forthrightly, allowing readers to use their own theoretical orientations to interpret the findings. As such, we have deliberately avoided providing a prefabricated grid for interpreting the findings but, rather, present them inductively. While respecting the significant variations in contemporary qualitative methodology (Guba
\& Lincoln, 2004), we believe that leaving the application of theory to the reader is the most apt means of presenting our research findings in the present article (Glaser, 2003), and this is a generally accepted protocol for the particular qualitative tradition used in the present research study (Creswell, 2007).

\section{FINDINGS}

Elsewhere (Tse., Firmin, Angelini., \& Foster, 2006), we reported findings about college students' internal factors relating to tattooing decisions. These included symbolism, memorials, and reminders. Additionally, students in our sample expressed no second thoughts or regrets but, rather, spoke of possible future tattooing. Additionally, we also reported findings from studying students' religious tattoos (Firmin, Tse, Foster, \& Angelini, 2008). Here, we report on four emerged themes from the data that relate to external factors affecting participants' decisions to tattoo. Each was common among the responses provided by the participants in the study. First, they related particular concerns about health issues and gave the matter due deliberation when making their decisions to tattoo. Second, participants reported diminishing the influence of their parents when making decisions to obtain a tattoo. Third, participants in the study reported that they underscored the influence of their peers when making tattoo decisions. Fourth, the students in our study were acutely aware of social stigmas attached to tattooing practices, and this external influence was given weighted consideration before deciding to tattoo.

\section{Consideration of Health Issues}

When questioned, many of the participants acknowledged the importance of health issues in their decision to tattoo. They were all at least cognizant of health concerns that might present themselves if the process were 
to be approached without caution. Jessica, for example, was well aware of the common risks involving tattoos. She mentioned, "You could get any kind of blood born disease, pathogen, including HIV/AIDS. It could become infected; or you could be allergic to it." Chris mentioned a number of the same risks as Jessica, but he also highlighted a seldomconsidered concern that a new tattoo is, in effect, an open wound that requires special attention. He described:

I know if the lady used a dirty needle . . . I could have gotten a viral infection. I know if a little bit of an air bubble got put into my skin, it could cause an infection, like eat away my skin. If I didn't take care of the tattoo right, like putting the ointment on it, keeping it covered, do not let it get sunburn, I could have gotten an infection and could leave scarring. I know that if I fall on it, and scrape it, it's going to be a permanent scrape.

The most prevalent health issue mentioned was the hygienic conditions of tattoo parlors wherein students would be tattooed. Like most individuals in the study, Colleen investigated the cleanliness of the several locations before finally deciding on a parlor. She noted,

There were three tattoo parlors that I inquired about. I asked to see their equipment. I asked to see what kind of health protection they used, how clean the equipment was used, and how could I verify that it was clean. I did research; I went to the library and [researched] what were good practices and what were not.

Philip followed similar precautions as those of Collen. However, he did not mention any prior research; instead, he focused on the cleanliness of the equipment at the time of his appointment. Philip stated his concerns:

I think it's really important to make sure that the place you go to is sanitary, [that] they are using all new needles for every patient. I physically watched him set everything up and unwrap everything he was using on me. I think that is very important [to be] able to see what they are using and where it is coming from.

Unlike Collen or Philip who made personal inquiries regarding the sanitary condition of tattooing equipments, Kristin's assurance came as a result of a tattoo artist's conduct. Finding it somewhat humorous, she elaborated on her decision regarding a particular parlor with the following account:

We went [to the tattoo parlor] before for my friend's mother to get one, so we knew that the place. . . was really clean. It was not like it was dirty or anything. We saw [a] person reach over and the [tattoo artist] totally flipped out and was like "make sure you don't do that again, don't come across." They have a little border that you cannot walk past if you are not the one that is getting the tattoo or piercing, so I knew it was a good place to go.

Although acknowledging that infections and even diseases could result from the procedures, everyone in our sample was confident that the reasonable risk of harm was minimal in their parlors of choice. Whereas some were more meticulous in their considerations, others generally relied on a visual scanning of the place when making judgments of its sanitary condition. Timothy's sentiments serve as a good summary:

I mean you can obviously get different diseases if the place doesn't clean correctly or sanitize their equipment. Both places I went were really clean, they had a good reputation as far as their cleaning machine, they had their certificates, and all that stuff. I was confident that I was not in harm's way too much because of the process they go through with new needles and whatnot.

It is obvious that, despite acknowledging certain health concerns, all of the students in our study felt that their parlors of choice 
provided enough perceived margin of safety for them to be tattooed.

\section{Diminished Parental Influences}

Certainly, parental influences can affect an individual's choice to tattoo. Their reactions also can serve to impact those who have chosen to obtain tattoos, even years subsequent to obtaining it. A few participants reported receiving encouragements from their parents regarding their decisions to tattoos. Nathanael noted a moderate level of support that he received from his parents: "My mom, she wanted to get one; I don't think she ever will. My dad said he would never get one but they kind of supported me getting one." Erin, unlike most in the study, experienced strong support from her mother. She reminisced about the meaningful mother-daughter moment they shared as a result of her getting a tattoo: "My mom actually brought me to get one of them and she paid for it for my birthday present. . . . A week later, I was holding her hand while she was getting an old one re-done." In a few cases, participants experienced considerable support from one parent but little or no support from another.

The overwhelming majority of participants, however, did not report such benevolent parental support as Erin. Rather, they noted that their parents seemed to take a neutral or passive stance and never fully addressed the practices of tattooing with them or enforced any rules against obtaining them. Ellen recalled the general indifference she received from her parents, noting, "No, not really a rule, like my parents weren't exactly thrilled, because there's ... like the safety stuff and all that. They never had a rule about it." Similarly, Melanie recounted her parents' irresolute response to when she sought their opinions:

No, there were not [any] family rules against tattoos. When I [asked my parents if I could get a tattoo], I was sitting by the pool with my mom and I was like "What would you think if I got a tattoo?" and she was like ... "Oh, man." But she said, "Well, if you get something tasteful and not something ugly, you know, it's your choice, it's your money." There was not really anything against it. My dad was like "it's a bug!" And I was like "technically, yes." But yeah, there was no family rule, saying you must never ever get a tattoo.

Melanie's parents also demonstrated a general attitude to place the responsibility of choice or decision upon their children. For example, some parents would disapprove of their children getting a tattoo while they were young. However, when their children crossed certain age thresholds, then parents deferred their opinions to the choices of their children. Ben recounted,

I asked my dad, as a teenager, and he pretty much said no. Not to the extent that some people I have talked to said. Their parents would disown them if they ever got a tattoo. Pretty much, I was a rebel, like my parents. My tattoos kind of reflect ... or my tattoos in my life reflected upon my family. ... [Later], I asked my dad and my mom before I got it, if that would be okay with them. They pretty much said that I was 21 and could make my own decisions at this point in time. So I went and got it and I think that was actually nice that I kind of waited until I was old enough to make that decision for myself. It really did not have any impact on the family and I did not break any rules or create any conflicts because of it, which was good.

Some participants reported encountering particular friction with their parents over the decisions to tattoo. For instance, when asked about parental rules and responses to tattooing, Aaron reacted negatively to the question and began describing the difficulties his family faced:

Not when I got mine. When my brother got his, my dad threatened to not pay 
his tuition and I think my mom cried. [Perhaps unwillingly], they kind of realized that I'm 18 or 21 or whatever and I'm an adult. [But] I think my brother broke the ice for me.

Without a family forerunner to clear the way, a few resorted to convincing their parents to allow them to obtain a tattoo. Andrea found it necessary to try to change her parents' earlier decision to disallow tattoos and found a way to resolve their differences. She conveyed the following dialogue between her mother and herself:

I was not allowed to have more than two piercings and a cartilage. ... I was not allowed to have my face pierced. My mom and I actually made a deal, because I wanted a tongue ring, just to see how it was. If I didn't like it, I would take it out. My mom said "OK, tattoo, but no facial piercings." I said "deal.”

We note that participants in the study were not easily swayed by their parents' comments. Although it certainly would be pleasant for students to hear positive feedback from their parents, no negative reactions or opinions on their parents' parts ultimately influenced the students' choices. Obviously, students who were swayed by their parents not to obtain any tattoos were not included in this study. Nevertheless, the majority of students in this study who obtained a tattoo did so regardless of the apprehensions or protests of their parents. In a poignant moment of disregard, Doug commented, "We had already talked about it, and I already knew what they would say, so I just went ahead and did it."

For some participants, thoughts of seeking advice from parents were overwhelming, so they neglected to notify their parents prior to obtaining their tattoos. Shelby reflected on her decision not to seek parental counsel or approval this way: "I didn't want them to try to stop me because I figured I'd get it anyway.
It's easier to ask forgiveness than permission." Similarly, Christi reasoned, "I didn't tell them because I just figured . . . my mom would give me a hard time and try to talk me out of it." Speaking with a tone of tension, Lori added, "I did not tell them. My dad always threatened that if I got a tattoo he would cut it off my body. . . . Well, he wouldn't, however they just think it's something stupid." These individuals seemed determined to live with whatever consequences their actions might bring from their parents or families. Beth's experience could well define the context of what many of the participants experienced: "My dad literally, even to this day . . . what is it . . 11 years later . . . the mention of it is just appalling to him.”

In sum, among these participants, the general indication was that students desired affirmations from their parents with regard to their wishes to tattoo. Ultimately, whether their parents were passive toward tattoos or outraged about such practices, these students generally were unswayed by parents in their choices and decisions. A different factor, peers, seemed to possess a more poignant role in this regard.

\section{Underscored Peer Influences}

Peer influences are different from parental influences relative to the strength of the participants' reported appeal of tattooing. In a number of instances, individuals obtained tattoos as a direct result of their friends having tattoos or encouraging them to obtain one. For example, consider Tim's comment:

When I started at Starbuck's, I met some guys [who had] really well done tattoos. ... After seeing ... the way that they express themselves through their tattoos, I was influenced to do the same. They were the ones who got me into it. I had always wanted one, but they ... influenced me a lot on getting mine ... working with people that have lots of tattoos and 
really good ones made me a lot more comfortable with it. . . It made me a lot more comfortable with just the fact that there are people that are making the same decision that I want to. It took the edge off of it. . . . It was something that I wanted to do and I think that being around people like that really gave me the courage to go out and actually make that decision, instead of just sitting on it and saying, "I'd really like one, but I don't know."

Such peer influences were echoed by most of students. For Jamie, tattooing involved participation in a growing trend among his friends: "Six out of 20 friends all got them around the same time, and so I think it was just domino effect. We all just decided to go get them." For others, a particular context or environment seem to dictate the perceived drive for tattooing. Adam noted, "Well, the [military] school itself. Well, I mean everybody, everybody had a tattoo." In most cases, some peer or social support was needed to encourage action. Brian recalled, "I took my brother-in-law to get the tattoo, as he had a lot of tattoos. He said it did not hurt that bad; it is not a big deal. A lot of that [decision] was just talking to people, and seeing what they thought about it."

Affirming peers or finding fit in a particular context were not the only indicated reasons for tattooing. Unwelcomed peer perceptions also influenced student's choices and decisions. Abby recalled her decision to obtain a tattoo based on certain negative reactions relating to her perceived image. She mentioned, "All my friends at high school considered me the goody-two-shoes kind of girl." So getting a tattoo seemed to be a way for her to combat this unsolicited wholesome attribution.

A number of participants acknowledged receiving negative comments regarding their tattoos or their decisions to tattoo. Still, these comments had seemingly little effect on their ultimate actions, although the comments left a negative impression nonetheless. As a case in point, Jannette recalled,

One girlfriend ... tried to talk me out of it with the "how horrible" and "how hard and hurtful" it was going to be. At one point I asked her, "Did you talk to my mom about this, is she paying you to say this?" But no, that was just her own thoughts toward it.

Consequences of tattooing can yield either pleasant or unpleasant peer responses. In Deb's case, she experienced an affirming response and surprise from her friends:

Actually before my 21st birthday I said I would never get one. [But in] my sophomore year, when I got it done, two of the girls [friends] actually bought it for me. They said, "This is really cool, we'll buy it for you for your birthday present, you're turning 21 ."

On the other hand, a number of students in this study had experienced tension and discouragements from their peers. Jenny remembered the disappointing responses of some of her friends: "I think a couple of my friends look down upon me and they do not view me as highly as they used to." Few young people are completely resilient to peer pressure. The sentiment expressed to Jenny was echoed by Steve as he recalled the discouragements he felt over the consistently downbeat responses from his schoolmates:

I was actually just discouraged by a lot of kids here at school because . . . what I got all the time was "how's that going to influence your job?" I never really understood the whole argument because it is on my arm. If I am a businessman, I will be wearing a suit, so it is not like I will ever see it. Even my roommate did not want me to have one; [he would remark] "Dude, how are you going to get a job with that?"

This sense of protest was, in fact, rather common among the participants in our study. 
Ryan's comments reflected the frustrations felt by those who have encountered disapprovals from their peers and friends:

\begin{abstract}
A lot people here on campus, if they saw it, they were shocked. Some of my good friends would not [have thought] that I would go out and do that. They have the right to have their own opinions. However, it made me feel like they were judging me, not that I can point fingers. I judge people and that is a hard issue because we all judge people. When you are the one being judged, it is hard. That's life too. You deal with those people everyday.
\end{abstract}

Obviously, regardless of others' opinions, the individuals in our study still decided to tattoo. The negative comments received after being tattooed drew more emotional reactions from participants than, seemingly, did responses prior to tattooing. As with the parental influence, peers who affirmed the participants' decisions to tattoo, understandably, were more celebrated than those who showed disapproval. Both parental and peer disapprovals were not met by the participants' expressed regrets but, rather, by their protests.

\section{Social Stigmas}

Participants disclosed that they believe many social stigmas are attached to the concept of tattooing. However, although students were cognizant of how some people stereotyped them for tattooing their bodies, the participants generally tended to discount these perceptions from others. Les, for example, stated, "There's definitely social stigmas involved with tattoos, I think that nowadays it has kind of worn off a little bit." We identified tattoo social stigmas relating to subculture identification, generational differences, socioeconomic status, and occupational differences. Participants identified some common subculture social stigmas, including the association of tattoos with bikers and drug addicts as well as rebellious and artsy individuals. Zach addressed the social stigmas as they pertain to drug addicts and bikers:

I think that a lot of times, if you see people with tattoos all over them, sometimes you think, depending on the kind of tattoo, like, maybe [they are a] druggy, ghetto kind of people. And then there is the biker-type tattoos that are like kind of trashy and so, I mean, I would say that I'm definitely aware of a lot stigmas that come with it.

Abby identified different stereotypes as follows:

It's kind of seen as like "Oh you have tattoos, you're kind of edgy or artsy or you're out there a little." There are always going to be people who see it as this crazy, rebellious, evil, kind of thing.

Social stigmas are important to address and understand, because they influence how people perceive themselves as well as how others perceive the respective perspective individuals. Cathy shared how her perception of social stigmas influenced her decision to obtain a tattoo: "I think that even though it is mainstream, it is still sort of a taboo thing and I kind of wanted to seem cool, I guess."

Generational difference was a prominent social stigma identified. Most participants believed that the present generation is more accepting of tattoos than have been previous cohorts. Josh noted,

In my generation I don't think it's as bad; like my parents see it as like bikers and loose people who get tattoos, but I think more so in our generation, that it is like the "hip" thing to do.

April identified younger people as being more tolerant than older individuals in this regard: "I think our generation is getting more modernized ... we learned more tolerance... . we learned to accept people for who they are." Julia had a similar opinion regarding people in the cohort age brackets of her parents and 
grandparents: "People are judgmental, and they don't really mean to be, but at times they are, especially with the older generation."

Participants believed that tattoos were becoming more culturally acceptable because more people were obtaining them. Cori said, "Yeah, they [tattoos] have become more accepted. A wider range of people... are getting them.... The culture at large has changed." Shawn noted that tattoos are becoming more popular, because people view them differently: "The culture today is more receptive because it's more of an art form now than it used to be."

Socioeconomic status was another social stigma identified throughout the interviews. Some participants, such as Justin, identified that tattoos often are viewed as a form of expression for the lower class and are not accepted for those in a higher socioeconomic circle:

I think a lot of people kind of equate tattoos [with] socioeconomic status, and they assume that if you're poor or uneducated you get tattoos, whereas someone of prominence or high education wouldn't get a tattoo, which I don't really agree with-that's why I got a tattoo. I think that people assume that you have to be pretty primitive and ignorant to get a tattoo, because "educated, sophisticated people" wouldn't get a tattoo. And I think a lot times that might stem from a lot of convicts and people who're in jails and prisons, a lot of times get more tattoos when they're there so, I think tattoos have a connotation to them, that they are kind of trashy.

Monica expressed an offshoot of this general idea. She addressed socioeconomic status through the particular tattoo design:

Generally, the people that just kind of get them for fun, I would think of as uppermiddle class, and then, people who do the whole body art, I see as I think those people that I've seen with them are tend to be a little bit lower class.
In a sense, participants indicated that tattoos sometimes were viewed in terms of social power. Individuals who choose to obtain tattoos may become perceived by others as having lost potential capital in terms of social power. The research literature does not indicate whether this perception is reality-but the perception is noted to be cogent, nonetheless. In sum, using various lines of reasoning, socioeconomic status plays a salient role in understanding certain social stigmas that undermine the tattooing practice, according to the participants in this study.

Occupational social stigmas were especially significant for the participants interviewed in this study, because each participant was a college student anticipating future employment. According to the location of the tattoo, occupational stigmas were a more severe concern for some. For example, an individual with a tattoo on his or her hand will have different concerns then an individual with a tattoo on his or her back. Of course, these stigmas also are subjective to the type of job the tattooed individual seeks. Earl explained his reaction to this stigma:

A lot of people said, "Oh dude you're going to have a tough time getting a job." I said, "Excuse me like when was the last time someone asked you to take off your shirt when you went in for an interview."

Unlike other individuals, Mark had less concern about this stigma, because his tattoo could be easily covered. Jed explained a hypothetical concern regarding tattoos in the workplace: "I guess if you had your whole arm tattooed and you walked around in short sleeves and you're supposed to be a business man it would be kind of awkward." Justin had a similar view: "If it's very visible, but if it's like concealed or something, like if it's like all up and down your arms I think, umm, they might be like kind of frowned upon, 
because its just, I think that's unappealing." In short, social stigmas play an important role in understanding the external dynamics toward tattooing in western society, and these were recognized by the participants in our study. We do not know what the different perceived "rules" were for various groups to which the participants referred in their interviews, but this phenomenon deserves further attention in future research.

\section{DISCUSSION}

Findings from the present study are relatively consistent with two findings indicated in the research literature. First, family members of students who choose to tattoo tend not to be very supportive of the decision. There were a few who encouraged the practice but, for the most part, parents and family members generally were discouraging of the practice. This finding from the present study is consistent with findings from Coe et al. (1993), who also found that immediate family members did not accept students' tattoos or they ignored them.

Second, peer relationships are particularly cogent in the decision to tattoo. As we noted, not all the participants' friends were supportive of the decision to tattoo. However, the participants consistently related that peers, acquaintances, and friends have significant influence in the decision to tattoo. Often, modeling principles seemed to be at work. This finding is consistent with Armstrong et al. (2004), who found social influences to be relatively strong among their sample of tattooed individuals.

These two consistencies among the reported literature are particularly noteworthy. At present, database searches show tattoo research literature to be relatively scarce. Consequently, it is important for future researchers in this domain to possess solid, empirical findings on which to base hypotheses and future quantitative studies. We believe that the present research study makes an apt contribution to that end.

We also note from the present study that students in our sample described themselves as being substantially influenced by peers-but they did not report significant peer pressure. Others who already had tattoos seemed to provide models for the participants in our sample. These model individuals also lowered some of the resistance threshold of our students. That is, as others who had tattoos and enjoyed them, these individuals helped to lower the inhibitions of our students, making them more likely to stop just considering it - and actually obtain tattoo themselves. The research literature regarding the potency of modeling among college students is well documented (Bandura, 2001). But these role models evidently did not pressure, verbally or otherwise, our participants to have tattoos. They did not urge participants to do so or explicitly or tacitly entice our participants to follow their examples.

It is noteworthy in our findings that tattooed students were aware of the social stigmas often attached with being tattooed. However, they discounted these stereotypes that potentially would be assigned to them by others - and decided to be tattooed anyhow. The participants did not portray themselves as being calloused to input from others. They received it. However, the students did not absorb the counsel from family members or friends who disapproved of their tattoo decision. Students simply were determined to go through with their decision, despite negative input.

We did not encounter cases of impulsivity or individuals being tattooed while intoxicated. There were no reported cases in our sample of mass tattooing (i.e., people going in large groups simultaneously to be tattooed) or 
decisions being made from dares. Rather, these were deliberate and carefully calculated decisions. Our participants seemed to be willing to endure whatever negative feedback they received and planned retorts to the criticism they were going to receive at times from family and friends. Not one of the participants expressed regret for the decision nor a desire to have the tattoo(s) removed. Holeywell (2007) suggested that, when regrets occur, they tend to be associated with individuals' physical aging and maturity.

In all, the participants in our study were somewhat self-willed individuals. That is, they were willing to cross friends and family at times in order to have what they wanted. A significant issue that we were unable to address in the study related to future perceptions of the participants. That is, would these individuals eventually mellow over time? Perhaps they later will regret the decisions made during their youth, particularly as they move into new seasons of life, obtain additional life responsibilities, and have children of their own for whom they will need to become responsible. In this vein, it is essential that we view the findings from the present study from a lifespan human developmental perspective. We captured students in a snapshot at one moment of their lives. The truer picture of these individuals can only be seen by following them over time and appraising how their perspectives change (or show stability) as they move through various stages in the adult development and aging process. We believe that this is an apt beginning point for better understanding tattooing practices among young adults_-but it is just that -a starting point.

At the time we entered the worlds of these young adults, they were college students who likely were struggling with identity issues-as all college-age students wrestle with individuality matters, to varying degrees. University life often involves leaving home for the first time, making new friends, and adopting or solidifying one's values. The college students in the present sample described their tattooing decisions to be cogent within this college student developmental process. Had they not chosen to enroll in college, they still would have faced significant developmental challenges, of course. And they may still have faced significant decisions of whether or not to tattoo. Nonetheless, we view the students in our particular sample through the lenses of young people undergoing the unique psychological challenges facing them that are unique to individuals choosing to place themselves in a university milieu.

\section{LIMITATIONS AND FUTURE RESEARCH}

All good research explicitly reports the limitations associated with a study (Price $\&$ Murnan, 2004). Because 94\% of students from the university where we conducted the study were Caucasians, the present sample lacks representation from minority individuals. Future studies should include minorities in the research design. Additionally, comparing the present findings in a future study of all minority students would provide valuable contextual comparison data. That is, do minorities and Caucasians differ in how they experience their decisions to tattoo? We recognize that the construct of "minorities" likely is overly broad, given that differences exist among various ethnic groups (Banks, 2007). Consequently, focused future studies on particular minority groups (e.g., Blacks, Hispanics, Asians, Native American, etc.) might be more appropriate.

Our sample size was relatively small, as typically is the case with qualitative studies. Cope (2004) would have suggested that, for the present study, our sample size would be adequate for external validity by qualitative 
standards and Guest et al. (2006) and Neuman (2006) would have concurred, given the data saturation we experienced. It also is true, however, that qualitative research is context dependent. Consequently, additional studies are needed on other university campuses in order to assess how our particular sample's findings would be similar or different from other college student samples (Schafer, 2001).

Increasing the sample size may result in losing some of the detailed and thick descriptions obtained from the present qualitative sample. Nonetheless, survey research would be an apt approach to the present project in order to add potential breadth to our findings. Typically breadth and depth are necessary tradeoffs when selecting quantitative and qualitative designs (Johnson \& Christensen, 2004). Ethical issues likely would prevent true experimental approaches to this subject-we cannot place students into control and experimental groups, asking some to obtain a tattoo and others to remain tattoo-free. Consequently, survey research is the next logical step to take, following the present study.

An interesting potential alternative, however, relative to an experimental design would be the use of "temporary tattoos." Assuming they could be made to look realistic, but not permanent, then some potential experimental procedures might be possibleunder controlled ethical guidelines. Surveys, indepth interviews, and journaling might be apt data collection means for better understanding how college students come to make their decisions to tattoo and other important dynamics involved with the tattoo process.

Correspondence concerning this article should be addressed to Michael W. Firmin, Professor of Psychology, Cedarville University, 251 N. Main Street, Cedarville, OH 45314; firmin@cedarville.edu

\section{REFERENCES}

Arminio, J. L., \& Hultgren, F. H. (2002). Breaking out from the shadow: The question of criteria in qualitative research. Journal of College Student Development, 43, 446-461.

Armstrong, M. L., Owen, D. C., Roberts, A. E., \& Koch, J. R. (2002a). College tattoos: More than skin deep. Dermatology Nursing, 14, 317-323.

Armstrong, M. L., Owen, D. C., Roberts, A. E., \& Koch, J. R. (2002b). College students and tattoos: Influence of image, identity, family, and friends. Journal of Psychosocial Nursing, 40, 21-29.

Armstrong, M., Roberts, A., Owen, D., \& Koch, J. (2004). Toward building a comprehensive college student influences with body art. Issues in Comprehensive Pediatric Nursing, 27, 277-295.

Bandura, A. (2006). Toward a psychology of human agency. Perspectives on Psychological Science, 1, 164-180.
Banks, J. A. (2007). Educating citizens in a multicultural society. New York: Teachers College Press.

Bereska, T. M. (2003). How will I know a code when I see it? Qualitative Research Journal, 3, 60-74.

Bogdan, R. C., \& Biklen, S. K. (2007). Qualitative research for education (5th ed.). Boston: Allyn \& Bacon.

Coe, K., Harmon, M. P., Verner, B., \& Tonn, A. (1992). Tattoos and male alliances. Human Nature: An Interdisciplinary Biosocial Perspective, 4, 199-203.

Cope, C. (2004). Ensuring validity and reliability in phenomenographic research using the analytic framework of a structure of awareness. Qualitative Research Journal, 4, 5-18.

Creswell, J. W. (2007). Qualitative inquiry \& research design: Choosing among five approaches (2nd ed.). Thousand Oaks, CA: SAGE. 
Daytner, K. (2006, June). Validity in qualitative research: Application of safeguards. Paper presented at the 18th Annual Conference of Ethnographic and Qualitative Research in Education, Cedarville, $\mathrm{OH}$.

De Wet, J., \& Erasmus, Z. (2005). Toward rigor in qualitative research. Qualitative Research Journal, 5, 27-40.

Fereday, J., \& Muir-Cochrane, E. (2006). Demonstrating rigor using thematic analysis: A hybrid approach of inductive and deductive coding and theme development. International Journal of Qualitative Methods, 5(1). Retrieved from http:// www.ualberta.ca/-iiqm/backissues/5_1/PDF/FEREDAY.PDF

Firmin, M. (2006). Using interview waves in qualitative phenomenological research. In P. Brewer \& M. Firmin (Eds.), Ethnographic and qualitative research in education (pp. 175181). New Castle, UK: Cambridge Scholars Press.

Firmin, M., Tse, L., Foster, J., \& Angelini, T. (2008). Christian student perceptions of body tattoos: A qualitative analysis. Journal of Psychology \& Christianity 27, 195-20.

Flick, U. (2002). An introduction to qualitative research (2nd ed.). Thousand Oaks, CA: SAGE.

Frederick, C. M. \& Bradley, K. A. (2000). A different kind of normal? Psychological and motivational characteristics of young adult tattooers and body piercers. North American Journal of Psychology, 2, 380-394.

Gay, L. R., Mills, G. E., \& Airasian, P. (2008). Educational research (9th ed.). Upper Saddle River, NJ: Pearson.

Glaser, B. (1992). Basics of grounded theory. Mill Valley, CA: Sociology Press.

Glaser, B. (2003). The grounded theory perspective II: Description's remodeling of grounded theory methodology. Mill Valley, CA: Sociology Press.

Guba, E. G., \& Lincoln, Y. S. (2004). Competing paradigms in qualitative research: Theories and issues. In S. Hesse-Biber \& P. Leavy (Eds.), Approaches to qualitative research (pp. 17-38). New York: Oxford University Press.

Guest, G., Bunce, A., \& Johnson, L. (2006). How many interviews are enough? An experiment with data saturation and variability. Field Methods, 18, 59-82.

Hawkes, D., Senn, C. Y., \& Thorn, C. (2004). Factors that influence attitudes toward women with tattoos. Sex Roles, 50, 593-604.

Holeywell, R. (2007, April 4). A laser is shined on tattoo removal. USA Today, p. 7D.

Johnson, B., \& Christensen, L. (2004). Educational research: Quantitative, qualitative, and mixed approaches (2nd ed.). Boston: Allyn \& Bacon.

Koch, J. R., Roberts, A. E., \& Cannon, J. H. (2005). College students, tattooing, and the health belief model: Extending social psychological perspectives on youth culture and deviance. Sociological Spectrum, 25, 79-102.

Lewins, A., \& Silver, C. (2007). Using software in qualitative research. Thousand Oaks, CA: SAGE.

Marshall, H. (2002). What do we do when we code data? Qualitative Research Journal, 2, 56-70.

Mason, J. (2002). Qualitative researching (2nd ed.). Thousand Oaks, CA: SAGE.
Maxwell, J. A. (2005). Qualitative research design (2nd ed.). Thousand Oaks, CA: SAGE.

Millner, V. S., \& Eichold, B. H. (2001). Body piercing and tattooing perspectives. Clinical Nursing Research, 10, 424-441.

Merriam, S. (2002). Assessing and evaluating qualitative research. In S. Merriam (Ed.), Qualitative research in practice (pp. 18-33). San Francisco: Jossey-Bass.

Morse, J., Barrett, M., Mayan, M., Olson, K., \& Spiers, J. (2002). Verification strategies for establishing reliability and validity in qualitative research. International Journal of Qualitative Methods, 1(2). Retrieved from http://www. ualberta.ca/_iiqm/backissues/1_2Final/pdf/morseetal.pdf

Neuman, W. L. (2006). Social research methods: Qualitative and quantitative approaches (6th ed). Boston: Allyn \& Bacon.

Price, J. H., \& Murnan, J. (2004). Research limitations and the necessity of reporting them. American Journal of Health Education, 35, 66-67.

Raffanti, M. (2006). Is grounded theory becoming "ungrounded?": A comparative analysis of Glasserian, Straussian, constructivist, and situational approaches. Paper presented at the 18th Annual Ethnographic and Qualitative Research Conference, Cedarville, $\mathrm{OH}$.

Roberti, J. W., Storch, E. A., \& Bravata, E. A. (2004). Sensation seeking, exposure to psychosocial stressors, body modifications in a college population. Personality and Individual Differences, 37, 1167-1177.

Ryan, R. M., \& Deci, E. L. (2000). Self-determination theory and the facilitation of intrinsic motivation, social development, and well-being. American Psychologist, 55, 68-78.

Sanders, C. R. (1988). Marks of mischief: Becoming and being tattooed. Journal of Contemporary Ethnography, 16, 495-432.

Schafer, W. D. (2001). Replication: A design principle for field research. Practical Assessment, Research \& Evaluation, 7(15). Retrieved from http://PAREonline.net/getvn.asp? $\mathrm{v}=7 \& n=15$

Glaser, B. G. \& Strauss, A. L. (1967) The discovery of grounded theory: Strategies for Qualitative Research. Chicago: Aldine Publishing Company.

Schildkrout, E. (2004). Inscribing the body. Annual Review of Anthropology, 33, 319-344.

Seidman, I. (2006). Interviewing as qualitative research (3rd ed.). New York: Teacher's College Press.

Silverman, D., \& Marvasti, A. (2008). Doing qualitative research: A comprehensive guide. Thousand Oaks, CA: SAGE.

Strauss, A., \& Corbin, J. (1994). Grounded theory methodology: An overview. In N. K. Denzin \& Y. S. Lincoln (Eds.), Handbook of qualitative research (pp. 273-285). Thousand Oaks, CA: SAGE.

Ten Have, P. (2004). Understanding qualitative research and ethnomethodology. Thousand Oaks, CA: SAGE.

Tse, L., Firmin, M., Angelini, T., \& Foster, J. (2006, May). A qualitative assessment of internal factors for tattooing among college students. Poster session presented at the 18th Annual Convention of the Association for Psychological Science, New York, NY. 